\title{
Autonomy, patients' preferences, and leaving decisions to doctors
}

\author{
KM Boyd \\ Professor Emeritus, College of Medicine and Veterinary Medicine, University of Edinburgh, Scotland, UK
}

TITLE Predictors of hospitalised patients' preferences for physician-directed medical decision-making.

AUTHORS Chung GS, Lawrence RE, Curlin FA et al.

JOURNAL / Med Ethics 2012; 38:77-82. http://dx.doi.org/ I0.1 I36/ jme.2010.0406I8

DECLARATION OF INTERESTS No conflicts of interest declared.

\section{SUMMARY}

Respect for autonomy is regularly cited as the ethical reason why patients rather than doctors should decide about their own medical care. But do patients want to make these decisions? Building on earlier US studies which cast some doubt on this, Chung and colleagues investigated the views of over 8,000 inpatients in a large Chicago hospital, correlating their replies with their age, gender, health, educational and religious status. Around $70 \%$ of the patients were African-American, slightly more than half were female and without university education and most were 'fairly religious'. When asked whether they preferred first 'that my doctor offers me choices and asks my opinion' and second, 'to leave decisions about my medical care up to my doctor', $97 \%$ of the patients said that they wished to be offered choices and asked their opinion, and $67 \%$ said that they preferred to leave medical decisions to their doctor. The 'male, less educated, more religious and healthier' patients were, albeit marginally, 'more likely to want to leave decisions to their doctors'.

Discussing these findings, the authors speculate: that 'treatment with respect and dignity' may be more important for patient satisfaction than shared decisionmaking... adrift amidst a sea of treatment options'; that religious people may 'be more comfortable with the idea of submitting... to authority'; that 'women are more likely to prefer a collaborative style of communicating with their doctors'; and that, 'Possibly, educated patients have greater understanding of their medical conditions and treatment options'. That 'healthier' inpatients preferred doctors to decide contradicted an earlier outpatient study' suggesting the opposite, but such contextual differences made the only safe conclusion that 'what is true for some populations is not necessarily true for others'.

\section{REFERENCES}

I Levinson W, Kao A, Kuby A et al. Not all patients want to participate in decision making. A national study of public preferences. J Gen Intern Med 2005; 20:531-5. http://dx.doi. org/I0.IIII/j.I525-I497.2005.04I0I.x

\author{
Correspondence to KM Boyd, \\ College of Medicine \& \\ Veterinary Medicine \\ University of Edinburgh \\ Biomedical Teaching Organisation \\ Medical School \\ Teviot Place \\ Edinburgh EH8 9A, UK
}

tel. $+44(0) 1316503109$

e-mail

K.Boyd@ed.ac.uk

\section{OPINION}

Emanating from the USA, where respect for autonomy is often said to 'trump' the other medical ethical principles of beneficence, non-maleficence and justice, the preference of so many patients to leave medical decisions to their doctor may seem surprising. As the authors admit however, results from 'an urban hospital with a predominantly African-American patient population... cannot be readily generalised to other patient populations'.

Ethically more challenging is the paper's apparent assumption that exercising autonomy requires competent patients to actively participate in each and every decision to be made about their medical care and treatment. The difficulties, both practical and philosophical, inherent in this assumption have been ably exposed by O'Neill' and Tauber, ${ }^{3}$ but at its simplest: why shouldn't the exercise of autonomy or self-determination by a competent adult involve determining when to trust the judgement of someone with much greater knowledge and longer experience of relevant medical treatment options someone moreover who (as the patients in the study were primed to be aware), may have already earned their trust by offering them choices and asking their opinion? The danger of framing such questions in terms of an ethical conflict between 'patient autonomy' and 'medical paternalism' can be seen perhaps in the authors' speculation that religious people may 'be more comfortable with the idea of submitting... to authority'. This of course is quite possible, but a no less possible interpretation is that they may, in general, be more trusting and less suspicious people.

2 O'Neill O. Autonomy and trust in bioethics. Cambridge: Cambridge University Press;2002.http://dx.doi.org/I0.1017/CBO97805 II606250

3 Tauber A Patient autonomy and the ethics of responsibility. Cambridge, Mass.: MIT Press; 2005. 